\title{
BIOPOLÍTICA E CONFISSÃO: CENAS DO GRUPO TERAPÊUTICO COM
} PACIENTES OBESOS BIOPOLITICS AND CONFESSION: SCENES OF GROUP THERAPY WITH OBESE PATIENTS

\author{
Shirley Dias Gonçalves e Luciana Lobo Miranda \\ Universidade Federal do Ceará, Fortaleza, Brasil
}

\section{RESUMO}

Este trabalho é baseado numa pesquisa realizada em um hospital público, especializado em cirurgia bariátrica na cidade de Fortaleza- CE e teve como objetivo investigar os discursos que circulam no grupo terapêutico realizado com pacientes diagnosticados obesos e como esses pacientes são subjetivados por esses discursos. A metodologia utilizada foi a observação participante do referido grupo composto por pacientes de ambos os sexos que estavam na fase pré e pós-operatória. Foram analisados dois dispositivos presentes no controle da obesidade: a biopolítica e a confissão. A cirurgia bariátrica funciona como uma estratégia biopolítica que incide sobre o corpo de uma população obesa e a confissão atua como tecnologia de si. Assim, esse trabalho buscou problematizar como o corpo obeso é demarcado por práticas de saber-poder que o constituem. Também se tratou de analisar as resistências ao discurso médico-científico sobre saúde, beleza e boa forma dos corpos.

Palavras-chave: biopolítica; confissão; obesidade; cirurgia bariátrica.

\section{ABSTRACT}

This work focuses on a research conducted in a Brazilian community hospital specialized in bariatric surgery (in Fortaleza, state of Ceará) with the aim of analyzing therapy group discussions with obese patients and how the patients are subjected by these discussions. The research used participant observation methodology. The group was composed of both male and female patients in the pre- and post-operative periods. Two obesity control devices were analyzed: biopolitics and confession. Bariatric surgery acts as a biopolitical strategy on the obese population body, and confession works as a technology of the self. Therefore, this work questioned how knowledge-power practices determine an obese body. Additionally, the research analyzed the resistance to medical-scientific discussions regarding body health, beauty and fitness.

Keywords: biopolitics; confession; obese patients; bariatric surgery.

\section{Introdução}

Fique nu... mas seja magro, bonito, bronzeado!

(Foucault, 1979/2008a)

A epígrafe, presente na entrevista-artigo "Podercorpo" do livro Microfísica do Poder, data de 1979. Ao ser questionado como a publicidade e a pornografia teriam recuperado o corpo enquanto investimento do poder, Foucault (1979/2008a) aborda as tensões entre libertação e controle, afirmando: "Como resposta à revolta do corpo, encontramos um novo investimento que não tem mais a forma de controle-repressão mas de controleestimulação" (Foucault, 1979/2008a, p. 147). Passados mais de 30 anos, o controle-estimulação que nos fala o pensador parece ter se capilarizado com novos agentes e instituições, em exigências contemporâneas por um corpo perfeito, dito magro. Diariamente somos (in)formados por revistas impressas, sites, programas telejornalísticos sobre os limites e alcances de prática de esportes, dietas e intervenções cirúrgicas para nos tornarmos um exemplo de corpo belo e saudável.

O corpo ocupou um lugar de grande relevância nos estudos de Michel Foucault, pois, para o filósofo, mais do que consciência ou ideologia, o controle da sociedade, sobretudo a capitalista, opera nos indivíduos prioritariamente através do corpo (Foucault, 1979/2008a). No entanto, Foucault não se propôs a definir o que eram corpos, mas como se chega a produzi-los em práticas discursivas e não discursivas, ou seja, como os corpos 
flagelados medievais se transformaram em corpos produtivos (nas fábricas), em obedientes (nas escolas) e, aqui podemos acrescentar, em obesos (na clínica médica), em "sarados" (nas capas de revistas), em sexuados (nos mais diversos lugares). Assim, interessa-nos produzir ecos para a questão que Foucault lançou em "Poder-Corpo":

do século XVII ao início do século XX, acreditou-se que o investimento do corpo pelo poder devia ser denso, rígido, constante, meticuloso. Daí, esses terríveis regimes disciplinares que se encontram nas escolas, nos hospitais, nas casernas, nas oficinas, nas cidades, nos edifícios, nas famílias... E depois, a partir dos anos setenta, percebeu-se que esse poder tão rígido não era assim tão indispensável quanto se acreditava, que as sociedades industriais podiam se contentar com um poder muito mais tênue sobre o corpo. Descobriu-se, desde então, que os controles da sexualidade podiam se atenuar e tomar outras formas... Resta estudar de que corpo necessita a sociedade atual... [grifo nosso]. (Foucault, 1979/2008a, p.147-148).

$\mathrm{Na}$ sociedade ocidental atual, o corpo ocupa uma centralidade, tendo em vista que os modos de subjetivação são deslocados para a exterioridade somática. O cuidado, antes voltado para o desenvolvimento das qualidades morais e sentimentos, dirige-se para a busca da saúde, beleza, jovialidade e longevidade (Costa, 2004). O corpo é visto como apresentação de si (Le Breton, 2003), como lugar "privilegiado da subjetividade de cada um" (Sant'anna, 2002, p. 102) ou como corpolatria, isto é, idolatria à forma física do corpo (Fontes, 2007).

E como ficam aqueles corpos desviantes, doentes, que excedem por serem gordos, obesos para os atuais padrões ocidentais? Que marcas carregam aqueles corpos submetidos a uma intervenção cirúrgica chamada bariátrica? Como esses corpos são marcados pelos discursos acerca da obesidade?

A obesidade é definida pelo discurso médico como uma doença crônica de etiologia multifatorial caracterizada pelo acúmulo excessivo de gordura corporal e se configura como um problema de saúde pública nos países desenvolvidos devido aos riscos e comorbidades que a acompanham, tais como: hipertensão arterial, dislipidemia, diabetes tipo 2, apneia do sono, entre outras (Fadiño, Benchimol, Coutinho, \& Appolinário, 2004). No Brasil, o Ministério da Saúde (2009) produziu dados que apontam o aumento da obesidade nos brasileiros, sendo $13,6 \%$ o índice em mulheres e 12,4\%, em homens. Segundo informações da pesquisa Vigilância de Fatores de Risco e Proteção para Doenças Crônicas por Inquérito Telefônico - Vigitel do Ministério da Saúde, a cidade de Fortaleza é a segunda capital brasileira com o maior índice de obesos: 18,2\% (Fortaleza, 2011).
A indicação do tratamento da obesidade por meio da cirurgia bariátrica ou gastroplastia, isto é, cirurgia que consiste na redução do estômago para obter a diminuição do peso, vem crescendo nos dias atuais (Fadiño et al., 2004). Os pacientes indicados para tratamento cirúrgico são os que estão com Índice de Massa Corpórea (IMC) maior que $35 \mathrm{~kg} / \mathrm{m}^{2}$, associado a comorbidades e acima de $40 \mathrm{~kg} / \mathrm{m}^{2}$ (Fadiño et al., 2004).

Tomando como ponto de partida essas questões, configura-se como objetivo do presente artigo analisar os discursos que circulam no grupo terapêutico realizado com pacientes diagnosticados obesos, da Unidade de Cirurgia Bariátrica e Metabólica de um hospital público de Fortaleza, e como esses pacientes são subjetivados por esses discursos, tornando-se sujeitos da cirurgia bariátrica.

Este trabalho tem como referência os estudos de Michel Foucault (1970/1996b, 1979/2008a, 1969/2008b, 1976/2009) e de alguns de seus intercessores, a exemplo de Ortega (2002), Sant'Anna (2002) e Dreyfus e Rabinow (1995), para os quais os modos de subjetivação operam como dispositivos historicamente constituídos em práticas de saberes e poderes que produzem o sujeito. Tendo como eixo norteador a recusa à busca de origens e a constituição histórica do conhecimento (Foucault, 1973/1996a), não tomamos como verdade os discursos biomédicos hegemônicos, que tratam a obesidade enquanto um fenômeno de doença, e sim nos interessa, a partir disso, questionar e problematizar discussões sobre os efeitos de verdade e as possibilidades de resistências que esses discursos produzem.

Com base no conceito de práticas discursivas de Foucault (1970/1996b, 1969/2008b), abordaremos as descontinuidades existentes entre corpos gordos e obesos, além de evocar a centralidade do corpo na produção subjetiva contemporânea.

$\mathrm{Na}$ análise dessa teia discursiva acerca da obesidade que envolve relações de saber-poder, daremos atenção a dois dispositivos presentes na Unidade de Cirurgia Bariátrica e Metabólica do hospital onde foi realizada a pesquisa, separados apenas por efeito didático, mas que, na realidade, se entrecruzam: a biopolítica e a confissão. A primeira engendra-se no corpo-população e a segunda no corpo-sujeito. Por fim, abordaremos as possibilidades de resistências.

\section{As condições da pesquisa}

A pesquisa foi realizada na Unidade de Cirurgia Bariátrica e Metabólica de um hospital público de referência neste tipo de cirurgia, na cidade de Fortaleza-CE, com 
experiência desde janeiro de 2002. A Unidade realiza em média oito procedimentos cirúrgicos por mês. A técnica cirúrgica utilizada é a Gastroplastia de Fobi-Capella, que consiste em criar uma pequena bolsa na parte superior do estômago, restringindo o órgão e, consequentemente, a quantidade de alimento capaz de ser consumido, bem como em realizar um desvio de uma parte do intestino delgado, retardando a mistura do alimento com os sucos digestivos para evitar a absorção calórica completa.

Nos anos de 2009 e 2010, ocupamos o território da referida Unidade povoado por médicos, enfermeiros, nutricionistas, psicólogos e, principalmente, pacientes diagnosticados como obesos, seja na fila da cirurgia bariátrica, seja com operações recém-realizadas.

O projeto de pesquisa foi submetido e aceito no conselho de ética do referido hospital. Os pacientes que fizeram parte da pesquisa assinaram o termo de consentimento livre e esclarecido e tiveram seus nomes alterados para resguardar o sigilo e preservar o anonimato.

Buscamos nos alinhar com a atuação dos princípios micropolíticos da pesquisa-intervenção (Aguiar \& Rocha, 2007). A pesquisa foi construída com o auxílio de ferramentas tais como: observação participante durante as visitas ao hospital, conversas informais com pacientes, acompanhamento e participação nas reuniões mensais e no grupo terapêutico e restituição da pesquisa ao grupo. Todos os encontros foram gravados em áudio e transcritos com o consentimento dos participantes da pesquisa.

Nas reuniões mensais participam a equipe técnica da Unidade de Cirurgia Bariátrica e Metabólica, os pacientes operados e candidatos à operação. O objetivo dessas reuniões é fornecer aos pacientes informações explicativas sobre a cirurgia (riscos, complicações cirúrgicas, resultados, benefícios esperados), bem como esclarecer as dúvidas dos usuários do serviço.

O grupo terapêutico acontece na sala utilizada pela Psicologia e pela Nutrição no ambulatório do hospital. O grupo é aberto, de modo que os pacientes podem entrar ou sair a qualquer momento, sem precisar receber alta da psicóloga. Houve a participação em sete encontros do grupo terapêutico, com duração de aproximadamente 1 hora cada. O grupo era formado, em média, por treze integrantes de ambos os sexos, e era conduzido pela psicóloga da unidade. Ao final da pesquisa, realizou-se uma restituição ao grupo a fim de discutir os aspectos mais relevantes observados no decorrer dos encontros.

$\mathrm{Na}$ presente análise, será dada ênfase ao grupo terapêutico, visto que além de ter sido o território mais sistemático habitado pela presente pesquisa, há um forte demarcador psi, pois é conduzido pela psicóloga da Unidade.

No cotidiano do hospital para entrar na fila da cirurgia bariátrica, o paciente deve possuir Índice de Massa Corpórea (IMC) igual ou superior a 40, independente de comorbidades; intratabilidade clínica da obesidade há pelo menos dois anos; idade entre 16 e 65 anos e entre 65 e 70 anos com boas condições clínicas, dentre outras características. O paciente dá entrada no sistema através do posto de saúde que o encaminha ao tratamento no hospital. Na primeira consulta, o médico-cirurgião do ambulatório de cirurgia da obesidade o direciona para uma série de especialistas e exames, dentre os quais inclui pneumologista, cardiologista, nutricionista e psicólogo. Durante esse período, esse corpo é demarcado, esquadrinhado, medido, porém nem sempre é ouvido aquém e além de sua marca de obesidade.

A grande quantidade de demanda, a extensa lista de consultas e exames e a demora de agendamento acabam muitas vezes por tornar sem validade exames apresentados na consulta marcada, tornando-se queixa comum entre os pacientes, a exemplo do seguinte relato: "Não é fácil marcar os exames. É difícil e você não faz só uma vez. Eu tenho uma porção de exames de todo esse tempo. Quando chega aos médicos, os exames já estão todos vencidos" (Estela).

Por outro lado, mesmo criticando alguns encaminhamentos anteriormente descritos, há na fala dos pacientes uma valorização do que é público. Tal valorização é percebida na rotina de atendimento, na relação construída com a equipe de especialistas, dentre elas, com o próprio serviço de psicologia, que não os vê como uma cifra. "Eu tenho amigos que fizeram [a cirurgia bariátrica] pelo plano particular, que vêm atrás de mim pra conversar. Se eles são preparados, eles são muito mal preparados. Nós, pelo SUS, somos muito mais preparados do que eles" (Abelardo).

\section{Corpo Gordo e Corpo Obeso: descontinuidades discursivas.}

Em toda sociedade a produção de Discurso é ao mesmo tempo controlada, selecionada, organizada e redistribuída por certo número de procedimentos que tem como função conjurar seus poderes e perigos, dominar seu acontecimento aleatório, esquivar sua pesada e temível materialidade. (Foucault, 1970/1996b, pp.8-9)

O conceito de discurso em Foucault é de fundamental importância para entender as descontinuidades existentes entre o corpo gordo e o corpo obeso. $\mathrm{O}$ pensador recusou 
as representações e interpretações de uma essência ou sentido oculto por trás do discurso. Em sua tarefa arquegenealógica, não há uma verdade a ser desvendada (Lima, 2010). Para Foucault, é preciso tentar ficar no nível do próprio discurso, sendo necessário empreender a tarefa de considerar os discursos não como conjuntos de signos e significantes que se referem a determinados conteúdos, e sim como práticas, práticas discursivas, que formam sistematicamente os objetos de que falam (Foucault, 1969/2008b). Foucault define discurso como um conjunto de enunciados, com uma realidade material, com uma existência transitória, mas com uma duração que não depende da existência de um sujeito individual.

O estudo dos discursos, como dobra da relação saber-poder, é "uma análise das condições históricas de possibilidade (do a priori histórico) que fizeram que em um determinado momento somente determinados enunciados tenham sido efetivamente possíveis e não outros" (Castro, 2009, p. 177).

Dentre alguns princípios para a análise do discurso, Foucault (1969/2008b) destaca a descontinuidade. Ao falar das transformações discursivas com relação à loucura, Foucault trabalha, sobretudo, com as rupturas existentes entre a loucura e a doença mental. Essa envolve novas instituições, rituais e exigências não existentes para circunscrever a loucura: "Jamais, antes do século XVIII, um médico teve a idéia de saber o que era dito (como era dito, por que era dito) nessa palavra que contudo, fazia a diferença" (Foucault, 1970/1996b, pp. 11-12). Assim, não se trata de um mesmo objeto que se relativiza ao longo da história, deixando pouco a pouco as vias da loucura e transformando-se em doença mental. Diz Foucault (1969/2008b, pp. 52-53): "Os discursos devem ser tratados como práticas descontínuas, que cruzam por vezes, mas também se ignoram e se excluem".

Nesse ensejo se inscrevem as modificações discursivas que constituem o corpo gordo e o corpo obeso. Trata-se de conjunturas distintas, com diferentes instituições, enunciados, rituais que os produzem. Há uma descontinuidade desde o período renascentista até a atualidade, na maneira de conceber a beleza relacionada ao corpo. Na Renascença, o corpo gordo e rechonchudo era valorizado e exaltado, sendo representado em obras de arte, como pinturas e esculturas, principalmente na figura de mulheres corpulentas, de quadris largos e colo farto, tal como afirma Del Priore (2000, p. 8):

O corpo devia ser "entre o magro e o gordo, carnudo e cheio de suco", segundo um literato francês. A "construção", como dizia-se então, tinha que ser de boa carnadura. A metáfora servia para descrever ombros e peito fortes, suportes para seios redondos, e costas em que não se visse um sinal de ossos.
No século XIX, a gordura razoável denotava riqueza, a aparência gorda dizia o quanto de alimento a pessoa consumia e, portanto, a parte que ela atribuía a si da distribuição da riqueza social. A gordura era associada à saúde, à prosperidade e à beleza, enquanto a magreza era a doença, o definhamento do corpo (Fischler, 1995).

$\mathrm{Na}$ atualidade, a sociedade ocidental concebe como belo o corpo magro e esbelto, sendo, portanto, a gordura rechaçada. Se o corpo gordo era constituído por uma formação discursiva própria do senso-comum, sem critérios mensuráveis, que oscilaram entre a valorização e o preconceito em nossa história, o corpo obeso é constituído na esfera médica. Assim, as terminologias gordo e obeso são diferentes, sendo o termo obeso definido segundo critérios da biomedicina, enquanto a categoria gordo não segue esse parâmetro (Vasconcelos, Sudo, \& Sudo, 2004). A palavra "gordo", atualmente, tem recebido uma conotação de ofensa, que legitima o preconceito e a discriminação contra grupos sociais, enquanto o vocábulo "obeso" ou "portador de sobrepeso" é considerado politicamente correto, uma tentativa da ciência de propor uma neutralidade asséptica ao termo (Mendonça, 2010).

Esta descontinuidade entre corpo gordo e corpo obeso inscreve-se na crescente medicalização da sociedade a partir do séc. XVIII e no surgimento da biomedicina em suas relações com o capitalismo (Rabinow \& Rose, 2006). A biomedicalização tem as novas tecnologias reprodutivas como tema de destaque na mídia, na justiça e na política, mas não se reduz a estas, incluindo também novas técnicas de modificação dos corpos que lançam mão de novas drogas e/ou tecnologias, a exemplo da cirurgia bariátrica.

O discurso da obesidade como doença estabelece-se no sistema de dispersão, em que diversos enunciados o constituem, isto é, o obeso, como objeto do olhar médico, requer medidas de classificação do grau de obesidade, medicalização da patologia, cirurgia como forma de tratamento, dentre outros.

O corpo obeso circunscrito à esfera médica denota um estatuto de vontade de verdade. Essa, dentre os procedimentos de controle e delimitação do discurso interdição e segregação da loucura -, destaca-se como principal procedimento de exclusão presente em nossa sociedade (Foucault, 1970/1996b). O pensador francês entende por verdade um conjunto de procedimentos regrados para a produção, a colocação em circulação e o funcionamento dos enunciados, bem como a relaciona aos sistemas de poder que a produz e aos efeitos de poder que a induz (Foucault, 1975/1999).

Este sistema de exclusão apoia-se em diversas práticas institucionais: científicas, médicas, pedagógicas, midiáticas 
que valorizam, reconduzem e distribuem essa vontade de verdade. A mídia, por exemplo, participa desse sistema, auxiliando a constituir o discurso médico como legítimo a falar sobre o corpo obeso. Podemos citar a figura do especialista, autoridade que dá entrevistas, por exemplo, na televisão (Miranda, 2009). Apesar de se encontrar numa cena enunciativa onde se prioriza a necessidade de falar para "todos", pois a televisão, ao buscar audiência, deve prescindir de uma terminologia mais hermética típica do saber científico, é em nome da ciência que o especialista fala. Desse modo, os discursos que produzem saber científico são tomados como verdadeiros, e isso lhes confere poder, pois, conforme Araújo (2008, p. 235), "a partir do momento em que um saber usa o discurso de verdade, seu exercício implica exclusão, separação, interdito, enfim, poder".

Assim como efeitos de verdade, podemos citar a construção de medidas que avaliam e classificam corpos em territórios da saúde, tais como: magro (IMC abaixo de 20) e normal (IMC entre 20-25); e territórios de doença, como: sobrepeso (IMC entre 25-30), obesidade leve (IMC entre 30-35), obesidade moderada (IMC entre 35-40) e obesidade severa ou mórbida (IMC acima de 40).

Desse modo, a concepção de corpo obeso é uma construção social produzida numa cultura e em períodos históricos específicos. Não é um conhecimento pronto e um dado a priori e sim tecido nas redes discursivas engendradas pelo social. Nessa perspectiva, corroboramos com Lima (2008, p. 144) ao afirmar que:

O corpo não pode ser tratado como se fosse uma entidade originária passível de substancialização, naturalização. $\mathrm{O}$ corpo, sua produção, deve ser situado no campo das forças em jogo num dado momento histórico que o determinam de uma forma e não de outras.

A lógica do consumo do sistema capitalista torna o corpo como o lugar ideal para o investimento da economia de mercado e, assim, engendra o desenvolvimento de hábitos e de comportamentos, tais como: praticar atividades físicas, ter uma alimentação balanceada e saudável, mudar a aparência através de intervenções estéticas e cirúrgicas, bem como ficar atento aos sintomas e ameaças do corpo, procurando seguir rigorosamente as prescrições médicas (Couto, 2007). Comportamentos que denotam uma constante vigilância sob o corpo, em que cada indivíduo passa a ser responsável por geri-lo. Nesse viés, somos julgados como modelos a serem copiados ou evitados a depender da saúde e da aparência que possuímos.

Assim, constroem-se bioidentidades dos indivíduos responsáveis e também dos desviantes, aqueles que não se vigiam nem se controlam, considerados estultos e inábeis de cuidar de si (Ortega, 2002). É nesse contexto que se encontra o obeso, considerado desviante da norma. O Índice de Massa Corporal - IMC - funciona como medida, norma que demarca, classifica os corpos como "normais", com IMC entre 20 e $25 \mathrm{~kg} / \mathrm{m}^{2}$, e "anormais" os corpos acima desse valor. O corpo obeso parece ser considerado como anormal, conforme se pode observar no relato de uma paciente do grupo terapêutico, locus da presente pesquisa, quando se discutia sobre relacionamento amoroso heterossexual:

"Não entra essa ideia na minha cabeça de homem gostar de mulher gorda. Porque não é o normal. Pra mim, eu acho que uma mulher gorda não é o normal. Pra mim. Eu não me aceito gorda" (Berenice)

“E o que é o normal?" (Pesquisadora)

“O normal é magra. Eu acho que o normal é magra que é bom em todos os aspectos" (Berenice).

Encerrada nas práticas discursivas relacionadas ao saber médico, a obesidade deixa de ser possível causadora de doenças (diabetes, hipertensão, etc.) para ser em si mesma uma doença que, conforme será visto a seguir, requer prevenção e tratamento.

\section{Entre a Prevenção e a Correção: o controle da obesidade como estratégia biopolítica}

Durante um encontro do grupo terapêutico, uma paciente comentou que, atualmente, a obesidade é um assunto em voga na mídia televisiva. Referindo-se à presença de médicos em programas de televisão disse: "Eles querem fazer uma prevenção. Eles vão gastar muito mais com a cirurgia bariátrica do que se conscientizasse o obeso, a pessoa pra não chegar na obesidade". Como a obesidade passou a ocupar essa centralidade? Qual o interesse (bio)político de se prevenir a obesidade?

Segundo o médico-cirurgião da Unidade de Cirurgia Bariátrica e Metabólica do hospital, o objetivo da cirurgia é reduzir o peso dos pacientes obesos e os riscos de mortalidade da obesidade, de modo a regular e aproximar as taxas de mortalidade da obesidade aos parâmetros da população geral, não obesa, pois, conforme o médico: “ $A$ obesidade mórbida é aquela com aumento de mortabilidade [sic] até 12 vezes maior que nos magros". Assim, objetivase um controle da população, uma regulação do corpo social, de modo que a cirurgia bariátrica funciona como uma estratégia de biopoder, poder sobre a vida, poder sobre o corpo de uma população obesa. Em relação ao biopoder, Rabinow e Rose (2006, p. 37) definem como:

o conceito de biopoder procura individualizar estratégias e configurações que combinam três dimensões ou planos: 
uma forma de discurso de verdade sobre os seres vivos; um conjunto de autoridades consideradas competentes para falar aquela verdade; estratégias de intervenção sobre a existência coletiva em nome da vida e da morte; e modos de subjetivação, nos quais os indivíduos podem ser levados a atuar sobre si próprios, sob certas formas de autoridade, em relação a estes discursos de verdade, por meio de práticas do self, em nome da vida ou da saúde individual ou coletiva.

No grupo terapêutico operam-se algumas dessas táticas: o conjunto de práticas discursivas que funcionam como regimes de verdades (prescrições de dietas, hábitos, comportamentos e modos de viver em nome da saúde), especialistas (médicos, psicólogos, nutricionistas, etc.) que proferem essa "verdade", intervenções (clínicas, cirúrgicas) sobre a população obesa e subjetivação dos pacientes, que são enredados na teia do poder, nas estratégias de condução de condutas de si e dos outros.

Porém, conforme Latour (citado por Spink, Lisboa, \& Ribeiro, 2009), é necessário "algo mais" do que discursos e autoridades para legitimar o conhecimento na construção de fatos enquanto um problema de saúde pública. No caso da obesidade, é preciso juntar e enlaçar aos textos científicos: figuras (cartaz da pirâmide alimentar afixada na sala do grupo terapêutico, folhetos distribuídos aos pacientes), fotos (de pacientes antes e depois da cirurgia bariátrica), números, gráficos (taxa de incidência e de mortalidade de obesidade), tabelas (tabela de IMC), como os apresentados na reunião mensal do programa de cirurgia bariátrica do hospital.

É necessário ainda que um tema "instigue o interesse de diversos atores sociais, para atuarem como porta-vozes - isto é, falarem em nome de interesses de comunidades específicas, econômicas, políticas, sociais ou científicas" (Latour citado por Spink et al., 2009, p. 354). Dessa forma, pacientes do hospital são atores sociais que revelam chegar até o programa da Unidade de Cirurgia Bariátrica e Metabólica por indicação de amigos, bem como indicam a cirurgia bariátrica a outras pessoas obesas: "Uma amiga minha que fez [a cirurgia] aqui no ... [nome do hospital] me levou pra reunião. Foi mais de um ano me convidando. Como eu também fico chamando o povo pra reunião. Eu também não posso ver um [obeso] que eu convido" (Cristina).

Assim, a obesidade vai se configurando na rede social enquanto um problema de saúde pública através de dispositivos que a constituem. Esses são alguns dos elementos do biopoder, que utilizam estratégias, instrumentos emecanismosderegulação docorpoindividual e do corpo social - população, um controle focalizado nas formas de vida, nos modos de viver (Guareschi \&
Bernardes, 2007). Dentre essas práticas, podem-se citar: o modo de conduzir condutas por meio de prescrições da equipe técnica (comer de 3 em 3 horas, fazer 6 refeições diárias); a balança que, mesmo quebrada, faz-se presente na sala de grupo terapêutico, indicando a necessidade de mensuração, vigilância e controle do peso corporal; o cartaz da pirâmide alimentar também fixado na mesma sala, que prescreve a porção (quantidade) e qualidade de alimentação diária a ser ingerida; dentre outros. Em suma, essas práticas discursivas e não discursivas atravessam e vão ajudando a constituir o sujeito obeso, sujeito de uma intervenção cirúrgica bariátrica.

\section{A confissão como tecnologia de si presente no controle da obesidade}

“A pessoa é operada do estômago e não da cabeça, da mente. Não há cura para a obesidade, tem que ter autocontrole" (Maria)

Foucault (1976/2009) afirma que o sexo opera como dispositivo que diz a verdade do sujeito - dispositivo de sexualidade. Há uma estimulação e incitação a se falar sobre sexo através da técnica da confissão, definida por Foucault (1976/2009, p. 70) como "um ritual de discurso em que o sujeito que fala coincide com o sujeito do enunciado; é também um ritual que se desdobra em uma relação de poder". Desse modo, o filósofo trabalha menos com a hipótese repressiva da sexualidade do que com o regime de discursividade em que se insere o sexo a partir do século XVII.

No Ocidente, a verdade do sexo aparece em um procedimento de saber-poder denominado scientia sexualis, uma prática discursiva, na qual a técnica da confissão foi difundida para além da penitência cristã, atingindo a pedagogia, a medicina, a psiquiatria, a psicologia, a psicanálise, entre outros. Assim, o sexo, que antes era inscrito numa pastoral católica através da confissão dos pecados da carne, dos desejos, da vontade, ingressa na esfera da ciência, que estimula e incita a confissão de si, como vontade de verdade, instigando a falar a verdade sobre nós mesmos.

A partir do século XVIII, com a confissão e o exame como tecnologias de si, as intervenções sobre o sujeito passam a ser terapêuticas. A sexualidade torna-se uma questão médica, como afirma Foucault (1976/2009, p. 77):

A confissão ganhará sentido e se tornará necessária entre as intervenções médicas: exigida pelo médico, indispensável ao diagnóstico e eficaz, por si mesma, na cura. A verdade cura quando dita a tempo, quando dita a quem é devido e por quem é, ao mesmo tempo, seu detentor e responsável. 
Durante as reuniões mensais da Unidade de Cirurgia Bariátrica e Metabólica do hospital, a equipe técnica (médicos, psicólogos, nutricionistas) solicita e estimula os pacientes gastroplastizados a falarem de si, confessarem seus atos, comportamentos e hábitos alimentares antes e depois da cirurgia, a darem o seu depoimento sobre a experiência da gastroplastia. Adota-se o modelo testemunhal, onde é comum o elogio aos benefícios decorrentes da cirurgia bariátrica:

Eu tinha $194 \mathrm{~kg}$. Faz 8 meses que eu fiz a cirurgia e estou com $122 \mathrm{~kg}$ hoje. Tomava remédio pra diabete, hipertensão, joelho porque eu não andava. Eu ficava no andar de cima de casa e minha mulher levava minha comida. Nem descer escada eu conseguia. Hoje eu estou caminhando na praia. (João)

Observa-se também que alguns relatos no grupo terapêutico são expressivamente atravessados pelos discursos médicos acompanhados pelas prescrições desses profissionais. O discurso médico, como vontade de verdade e com status científico, atravessa os corpos, delimitando os hábitos que devem ser seguidos, não importando angústias, frustrações e também alegrias presentes nesse sujeito-corpo.

"É dito pelos médicos que a cirurgia não tem cura tanto como a obesidade. É um tratamento. É um tratamento pelo resto da vida. Tem um controle, mas a cura não tem. É comprovado cientificamente" (Silvana).

Tem gente que pensa que fez essa cirurgia e nunca mais vai engordar. Tire isso da cabeça. Isso não existe não. Ah porque eu posso comer tudo! Pode comer tudo, mas dentro do limite. ... Essa cirurgia não é garantia de ficar magro não. Ela ajuda. Você tem que fazer exercício físico. Tem que fazer academia. Se não tem dinheiro, bota um tênis e vai caminhar que é de graça, cuidado só pra não ser atropelado pelos carros. (Jorge)

Os testemunhos dos pacientes são marcados pelo discurso de que a eficácia do tratamento depende do paciente seguir corretamente as prescrições médicas, sem tentar enganar ou burlar a equipe técnica, como se pode observar nas falas dos próprios pacientes que dizem: "Faça tudo o que eles [médicos] mandarem, que você se dá bem" (Maria) ou ainda: "É difícil, mas se você seguir a regra dá certo" (Sabino).

As dificuldades com relação ao autocontrole também são incitadas a serem confessadas e discutidas pelo grupo como parte do tratamento, em que questões culturais e modos de vida dos pacientes muitas vezes são negados:

Eu fui criado quando criança a só comer três vezes por dia. Merendava, almoçava e jantava ... Nós merendávamos de manhã: leite com café, pão de milho, tapioca, ovos cozinhados. Tinha cinco litros de leite em cima da mesa e uma bacia de farinha d'água com rapadura para os trabalhadores lá de casa. A gente comia tudo o que tivesse na mesa. ... Almoçava e, quando era 19h, jantava. A gente jantava como gente grande. Quando eu vim pro doutor [citou o nome do médico], ele perguntou quantas vezes eu me alimentava e eu disse três vezes. Ele disse: "Tá errado".

... Eu vim me acostumar a comer seis vezes ao dia agora que eu comecei a fazer a dieta. (Luís)

O controle antes exercido sobre a sexualidade, parece ter se deslocado atualmente para a comida. Ortega (2002, p. 165) acrescenta que essa vem ocupando um lugar central em relação às preocupações biopolíticas no lugar do sexo, pois: "O tabu que se colocava sobre a sexualidade descolase agora para o açúcar e as gorduras. Os tabus passaram da cama para a mesa. O glutão sente-se com mais freqüência mais culpado que o adúltero".

No grupo terapêutico, a prática psi da confissão encontra-se voltada para a busca da verdade no interior do indivíduo, para o resgate de comportamentos aprendidos na infância em relação à alimentação a fim de ressignificálos na vida adulta:

Só depois da cirurgia, o que eu percebo, é que vocês vão imaginar ... pensar quando eu era com tal idade eu também fiz isso. Isso é importante pro emocional, isso é importante eu resgatar lá atrás. Como é que foi a minha infância em relação a minha alimentação, a própria amamentação: se eu fui amamentada, como era essa relação da minha mãe, a minha gravidez. Quem tem essa oportunidade de saber é importante porque eu vou relacionando e com 2 anos, 3 anos, 5 anos e 10 anos, como é que era? O que foi gerando cada vez mais as perdas que eu tive, as frustrações que eu tive enquanto criança? [grifo nosso]. (Psicóloga)

Os exercícios de refletirem sobre o passado para buscar "origens" desses hábitos e comportamentos alimentares são práticas prescritas constantemente no grupo terapêutico como estratégia para fazer os pacientes confessarem. A busca da verdade de si através da tecnologia da confissão encontra-se articulada com o modo de relação do sujeito consigo mesmo e com os outros. Quando os pacientes trazem à tona questionamentos, queixas e resistências sobre as dificuldades na rotina do hospital, o discurso psi os enquadram como fuga, como forma de não querer olhar para si: "Eles [os pacientes] não querem entrar no conteúdo interno. Ai fica falando, por que isso? Por que aquilo? Acho que você [referindo-se à pesquisadora] já viu o doutor [nome do médico] falando, na reunião geral, que não é pra gente resolver isso [referindo-se às queixas dos pacientes sobre o sistema de saúde]. É uma fuga" (Psicóloga). 


\section{Possíveis resistências?}

Ao invés de interpretar os discursos proferidos pelos pacientes no grupo terapêutico, procuramos participar, dispor a escuta da singularidade, abrir espaços para formas de resistências, para outros modos de existência numa aproximação da vida com a arte na busca de uma vida libertária e menos fascista. Fascismo que, segundo Foucault (2004), nos faz amar o poder e desejar o que nos domina (dietas; cirurgias bariátricas, plásticas; controle do peso; indústria da estética, etc.).

Como ressonância à experiência de participação do grupo terapêutico, questionamos: há, no grupo, uma escuta ao sofrimento do sujeito ou este se constitui como um espaço destinado a reforçar os discursos e prescrições médicas? Esse sofrimento estaria relacionado, como no discurso psi, apenas aos hábitos alimentares aprendidos na infância (amamentação, relação com a comida) ou às dificuldades cotidianas de pegar um ônibus, de fazer exames que são marcados, remarcados e perdem a validade, de ser alvo de preconceito nos espaços públicos e privados por ser considerado um ser disforme? Há possibilidades de resistências e de não sofrer, na sociedade em que vivemos, por ter um corpo dito obeso? Essas são questões para serem problematizadas.

Essa "matriz social" do sofrimento dos pacientes que circulam na Unidade muitas vezes não era considerada, vista como "resistência" a falar de si, a se confessar. No grupo terapêutico, o preconceito, as dificuldades do dia a dia e o hospital como instituição pública eram temas pautados constantemente pelos pacientes. A resistência no sentido foucaultiano (Foucault, 1995) aparece como inerente à relação de poder. Há no grupo resistência, pois os pacientes resistem a pensar-se apenas enquanto subjetivados por vetores familiares relacionados à infância. Os pacientes resistem ao dizer que o ônibus, a rua, a vizinhança, o hospital os subjetivam como sujeitos obesos e por sua vez, discorrem como ocupam ou não esse lugar nessa teia discursiva:

Precisa ter alguém que fale pelos diabéticos porque não é fácil você sair da sua cidade e vir pra cá. Você é obrigado a tomar coisas com açúcar, você treme, você sua, você passa mal e ninguém se liga nisso não. Eu vou falar uma coisa que eu não sei se é, mas eu vou falar e não vou abrir mão: "Vaidade da própria equipe". Vamos dar prioridade a esses que já fizeram todos os exames! Devia ser assim, mas não é não. O negócio é difícil. (Estela)

Faz-se necessária a crítica à culpabilização e à individualização da responsabilidade do paciente sobre seu corpo. Tendência esta também percebida na mídia, em campanhas governamentais que evocam a população a agir em prol da própria saúde. As condições reais de vida dos que procuram o serviço: se a localidade de sua habitação favorece ou não a prática de atividades físicas gratuita; se sua renda possibilita a compra de alimentos considerados mais saudáveis e a frequência a academias de ginástica; se as condições de trabalho permitem que ao fim da jornada ainda se tenha tempo/disposição para se exercitar, não podem ser desconsiderados.

Os discursos que excluem o social e enfatizam apenas o individual contribuem ainda mais para a culpabilização do paciente. Esses, ao mesmo tempo em que resistem, falando sobre suas condições de vida, assumem a culpa pelo corpo que carregam, como se dissessem: "só depende de mim mesmo".

No entanto, o grupo terapêutico parece também ser um lugar de encontro, de partilha, de subjetivação aquém e além da cirurgia. Não porque pacientes tenham que frequentá-lo antes e depois da cirurgia (afinal a entrada e saída no grupo é livre, não há alta, demarcando uma diferença do saber médico), mas porque pacientes acabam construindo um espaço de convivência, de troca de experiências diversas (não apenas sobre obesidade e cirurgia bariátrica, mas sobre relacionamento amoroso, relação com a família, com os amigos, etc.).

"A força da gente, é a força do grupo, ouvir os testemunhos" (Cristina).

"Quando eu não venho pra cá, eu sinto falta. Quando se junta um monte de obeso, a gente tem a mesma história ... Fica um ajudando o outro" (Rita).

Para além do controle dos corpos e da operação de seu estômago e de sua "mente", parece haver entre os pacientes uma forte solidariedade. Na união ao falar dos médicos, na valorização do espaço público, no enfrentamento dos deslocamentos urbanos, nas relações familiares e afetivas, em vários momentos, esses pacientes mostravam povoar um mesmo território existencial. Em suas falas, percebe-se o consentimento afirmativo de cabeça, um afago solidário que parece afirmar: "Eu sei do que você está falando, pois estamos no mesmo barco...".

Por meio das cenas vivenciadas no grupo terapêutico, discutiu-se, de um modo geral, a cirurgia bariátrica como uma estratégia biopolítica de regulação e controle da população obesa, bem como a estratégia de confissão para deixar falar a verdade de cada um.

A questão proposta não foi afirmar se os discursos sobre os corpos obesos são verdadeiros ou falsos, e sim problematizar como o corpo obeso é demarcado por práticas (discursivas e não-discursivas) de saber-poder 
que o constituem. Por fim, espera-se que este trabalho não seja uma discussão moral sobre como devemos ou não trilhar caminhos, mas sim elucide que os caminhos podem ser mudados e novos modos de existência podem ser inventados.

\section{Agradecimento}

à Coordenação de Aperfeiçoamento de Pessoal de Nível Superior - CAPES pela concessão de apoio financeiro a esta pesquisa através de bolsa de estudos.

\section{Referências}

Aguiar, K. F. \& Rocha, M. L. (2007, dezembro). Micropolítica e o exercício da pesquisa-intervenção: referenciais e dispositivos em análise. Psicologia: ciência e profissão, 27(4), 648-663. Acesso em 05 março, 2011, em http://pepsic. bvsalud.org/scielo.php?script $=$ sci arttext\&pid $=S 1414$ 98932007001200007\&lng=pt\&nrm=iso

Araújo, I. L. (2008). A noção de discurso em Foucault. In I. L. Araújo, Do signo ao discurso: introdução à filosofia da linguagem ( $2^{\mathrm{a}}$ ed., pp. 215-244). São Paulo: Parábola.

Castro, E. (2009). Vocabulário de Foucault: um percurso pelos seus temas, conceitos e autores. Belo Horizonte: Autêntica Editora.

Costa, J. F. (2004). A personalidade somática de nosso tempo. In J. F. Costa, O vestígio e a aura: corpo e consumismo na moral do espetáculo (pp.185-202). Rio de Janeiro: Garamond.

Couto, E. S. (2007). Uma estética para corpos mutantes. In E. S. Couto \& S. V. Goellner, Corpos mutantes: Ensaios sobre novas (d)eficiências corporais (pp. 41-54). Porto Alegre: Editora da UFRGS.

Del Priore, M. (2000). Corpo a corpo com a mulher: pequena história das transformações do corpo feminino no Brasil. São Paulo: Editora Senac.

Dreyfus, H. \& Rabinow, P. (1995). Michel Foucault. Uma trajetória filosófica: para além do estruturalismo e da hermenêutica (V. P. Carrero, Trad.). Rio de Janeiro: Forense Universitária.

Fandiño, J., Benchimol, A. K., Coutinho, W. F., \& Appolinário, J. C. (2004, janeiro/abril). Cirurgia bariátrica: aspectos clínicocirúrgicos e psiquiátricos. Revista Psiquiatria Rio Grande do Sul, 26(1), 47- 51. Acesso em 08 de novembro, 2009, em http://www.scielo.br/scielo.php?script=sci_arttext\&pid=S010181082004000100007\&lng=en\&nrm=iso

Fischler, C. (1995). Obeso benigno obeso maligno. Em: Sant'anna, D. B. (Org.). Políticas do corpo. São Paulo: Estação Liberdade.

Fontes, M. (2007). Os percursos do corpo na cultura contemporânea. In E. S. Couto \& S. V. Goellner, Corpos mutantes: Ensaios sobre novas (d)eficiências corporais (pp. 73-87). Porto Alegre: Editora da UFRGS.

Fortaleza é a segunda capital no país em obesidade. (2011, 19 de abril). Jornal O POVO. Acesso em 27 de abril, 2011, em http://www.opovo.com.br/app/opovo/brasil/2011/04/19/ noticiasjornalbrasil,2129652/fortaleza-e-a-segunda-capitalno-pais-em-obesidade.shtml

Foucault, M. (1995). O sujeito e o poder. In H. Dreyfus \& P. Rabinow, Michel Foucault, uma trajetória filosófica: para além do estruturalismo e da hermenêutica (pp. 231-249). Rio de Janeiro: Forense Universitária.

Foucault, M. (1996a). A verdade e as formas jurídicas. Rio de Janeiro: Nau ed. (Original publicado em 1973)

Foucault, M. (1996b). A ordem do discurso (17 a ed.). São Paulo: Loyola. (Original publicado em 1970)

Foucault, M. (1999). Em defesa da sociedade: Curso no Collège de France. (M. E. Galvão, Trad.). São Paulo: Martins Fontes. (Original publicado em 1975)

Foucault, M. (2004). Por uma vida não fascista. Acesso em 03 de fevereiro, 2011, em http://pt.scribd.com/doc/53047881/ Michel-Foucault-Por-Uma-Vida-Nao-Facista-PDF

Foucault, M. (2008a). Microfisica do poder (26 ed.). Rio de Janeiro: Graal. (Original publicado em 1979)

Foucault, M. (2008b). A arqueologia do saber ( $7^{\mathrm{a}}$ ed.). Rio de Janeiro: Forense Universitária. (Original publicado em 1969)

Foucault, M. (2009). História da Sexualidade I: A vontade de saber $\left(19^{\mathrm{a}}\right.$ ed.). Rio de Janeiro: Graal. (Original publicado em 1976)

Guareschi, N. M. F. \& Bernardes, A. G. (2007, janeiro/abril). Estratégias de produção de si e de biotecnologias. Psicologia em Estudo, 12(1), 151-159.

Le Breton, D. (2003). Adeus ao corpo: antropologia e sociedade. Campinas, SP: Papirus.

Lima, H. L. A. (2008). Verdade e conhecimento na perspectiva da vontade de poder em Nietzsche. In J. G. Vasconcelos, C. R. Muniz, \& R. K. G. Franco (Orgs.), Nietzschianismos (pp. 130-145). Fortaleza: Edições UFC.

Lima, H. L. A. (2010). Do corpo-máquina ao corpo-informação: o pós-humano como horizonte biotecnológico. Curitiba: Honoris Causa.

Mendonça, M. (2010, 08 de março). Em contexto: para enxergar além dos fatos. Revista Época, 616. Acesso em 24 março, 2010, em http://revistaepoca.globo.com/Revista/ Epoca/0,EMI125475-15215,00-EM+CONTEXTO.html

Ministério da Saúde. (2009, 07 de abril). 13\% dos brasileiros adultos são obesos. Acesso em 16 de setembro, 2009, em http:// portal.saude.gov.br/portal/aplicacoes/reportagensEspeciais/ default.cfm?pg=dspDetalhes \&id_area $=124 \& \mathrm{CO}$ NOTICIA $=10078$

Miranda, L. L. (2009, julho/dezembro). Linguagem e modos de subjetivação na relação práticas escolares e televisão. $O$ Público e o Privado, 14, 165-177.

Ortega, F. (2002). Da ascese à bio-ascese ou do corpo submetido à submissão do corpo. In M. Rago, L. B. L. Orlandi, \& A. L. Veiga-Neto (Orgs.), Imagens de Foucault e Deleuze. Ressonâncias nietzschianas (pp. 139-173). Rio de Janeiro: DP\&A.

Rabinow, P. \& Rose, N. (2006, abril). O conceito de biopoder hoje. Política e Trabalho. Revista de Ciências Sociais, 24, 27-57.

Sant'anna, D. B. (2002). Transformações do corpo: controle de si e uso dos prazeres. In M. Rago, L. Orlandi, \& A. Veiga-Neto, 
A. (Orgs.), Imagens de Foucault e Deleuze: Ressonâncias nietzchianas (pp. 99-110). Rio de Janeiro: DP\&A.

Spink, M. J. P., Lisboa, M. S. \& Ribeiro, F. R. G. (2009, abril/ junho). A construção do tabagismo como problema de Saúde Pública: uma confluência entre interesses políticos e processos de legitimação científica. Interface Comunicação Saúde e Educação, 13(29), 353-365.

Vasconcelos, N. A., Sudo, N. \& Sudo, I. (2004/março). Um peso na alma: o corpo gordo na mídia. Revista Mal-estar e Subjetividade, Fortaleza, 4(1), 65-93.

Recebido em: 18/01/2012

Revisão em: 09/03/2012

Aceite em: 29/03/2012

Shirley Dias Gonçalves é Psicóloga, Mestre em Psicologia pela Universidade Federal do Ceará (UFC). Ex-bolsista CAPES. Endereço: Rua Tenente Benévolo, 1082, apto 101, Meireles.
Fortaleza/CE, Brasil. CEP 60.160-040. Email: shirleydiasgoncalves@gmail.com

Luciana Lobo Miranda é Psicóloga, Doutora em Psicologia Clínica pela Pontifícia Universidade Católica do Rio de Janeiro, PUC - Rio. Professora do programa de Mestrado em Psicologia da Universidade Federal do Ceará (UFC). Endereço: AV da Universidade 2762. Benfica. Fortaleza/CE, Brasil. CEP 60020-180. Email: lobo.lu@uol.com.br

\section{Como citar:}

Gonçalves, S. D. \& Miranda, L. L. (2012). Biopolítica e confissão: cenas do grupo terapêutico com pacientes obesos. Psicologia \& Sociedade, 24(n.spe.), 94-103. 